\title{
Qualities and Aroma of Watermelon Juice during Storage
}

\author{
at $4^{\circ} \mathrm{C}$
}

\author{
Yu-bin WANG, Yue MA, Xiao-yan ZHAO and Chao ZHANG*
}

Beijing Vegetable Research Center, Beijing Academy of Agriculture and Forestry Sciences;

Beijing Key Laboratory of Fruits and Vegetable Storage and Processing;

Key Laboratory of Biology and Genetic Improvement of Horticultural Crops (North China), Ministry of Agriculture;

Key Laboratory of Urban Agriculture (North), Ministry of Agriculture, 50 Zhanghua Road, Haidian District, Beijing, China

${ }^{*}$ Corresponding author

Keywords: Watermelon, Pasteurization, Ultra High temperature, Aroma.

\begin{abstract}
The watermelon juice was pasteurized by the ultra-high temperature treatment, and stored at $4{ }^{\circ} \mathrm{C}$ for 2 weeks. The ultra-high temperature reduced the initial microbial counts of the watermelon juice. The aroma of the watermelon juice was reduced during the storage at $4{ }^{\circ} \mathrm{C}$ for 2 weeks. The typical volatiles were reduced from $52.1 \%$ to $37.2 \%$ during the storage.
\end{abstract}

\section{Introduction}

Watermelon (Citrullus lanatus) juice provides consumers with the moisture and some physiological functions as well [1]. The intake of the watermelon juice increases the plasma concentrations of lycopene, $\beta$-carotene [2] and arginine [3, 4]. Consequently, the juice reduces the chemical-induced hepatotoxicity [5] and proliferation of the cancer cell line [6] and relieves the muscle soreness of athletes [7].

The ultra-high temperature technique is the conventional way to inactive the bacteria of fruit juice [8]. The UHT is not only used in milk production, but also used for fruit juices, cream, soy milk, yogurt, wine, soups, honey, and stews [9]. The UHT treatment has effectively inactivated the bacteria of the watermelon juice [10] and maintained the aroma of the sugarcane [11]. However, the qualities and aroma of the pasteurized juice during the shelf life had not been evaluated to the best of our knowledge.

Therefore, the watermelon juice was pasteurized by the UHT treatment, and then stored at $4{ }^{\circ} \mathrm{C}$. The qualities and aroma during the storage were evaluated.

\section{Material and Methods}

\section{Processing of the Watermelon Juice}

Mature watermelon (Citrullus lanatus var. Jingxin No.3) was purchased from a local fruit market. The fruits were round with regular stripes and weighted about $3 \sim 4 \mathrm{~kg}$ per fruit. The flesh of the fruits was red with a soluble solid content of $11.5 \sim 13.5 \%$.

The fruits were peeled and squeezed in a Philips juicer after stored at $4{ }^{\circ} \mathrm{C}$ for $24 \mathrm{~h}$ (HR1861, Philips Co. Beijing, China). The juice was mix with complex food additive including arboxymethylcellulose sodium, ascorbic acid, xanthan gum, ethylene 
diamine tetraacetic acid, carminum, sodium pyrophosphate and etc.. The mixture was fully stirred and adjusted to the $\mathrm{pH} 4.10$ with the citric acid, and adjusted soluble solid content to 8.0 with the high fructose corn syrup (4502504-01, Fresh Juice Industry (Kunshan) Co. Ltd.). The formulated juice was homogenized at $50 \mathrm{MPa}$ (NS101L2K, GEA, Parma, Italy). The juice was pasteurized by the UHT treatment at $135^{\circ} \mathrm{C}$ for $2 \mathrm{~s}$. And then the pasteurized juice was stored at $4{ }^{\circ} \mathrm{C}$ for 2 weeks. The qualities and aroma of the UHT was evaluated at $1^{\text {st }}, 7^{\text {th }}$, and $14^{\text {th }} \mathrm{d}$, which nominated as the UHT1, UHT7, and UHT14. The juice before pasteurization was nominated as the Unpasteurized.

\section{Total Flora Counts}

Juice was serially diluted, plated in total count agar for total flora counts. The plates were incubated at $30{ }^{\circ} \mathrm{C}$ for $48 \mathrm{~h}$ and the bacterial colonies was counted manually.

\section{Electronic Nose Analysis}

The aroma of the watermelon juice was compared by the electronic nose (PEN2, Airsense Analytics GmbH, Schwerin, Germany). The electronic nose was turned on for $30 \mathrm{~min}$ and flushed the testing system for $180 \mathrm{~s}$. The sample of $2 \mathrm{~mL}$ was put in the testing tube. And then the electronic sensor was put into the testing tube to collect the results for $60 \mathrm{~s}$.

\section{GC-MS Analysis and Identification of Volatile Compounds}

An aliquot of $10 \mathrm{~mL}$ of the juice was put into a glass vessel. The glass vessel was placed in a water-bath at $30{ }^{\circ} \mathrm{C}$. The headspace was purged with a constant flow of nitrogen at $20 \mathrm{~mL} / \mathrm{min}$ for $10 \mathrm{~min}$. The volatile compounds were trapped in a glass capillary tube ( $3 \mathrm{~mm}$ internal diameter), and then disconnected from the system and placed in a Chrompack TCT/PTI 400 injector.

The volatiles of the sample were performed on an Agilent $6890 \mathrm{GC}$ coupled to an Agilent 5973I MS (Agilent Technologies, Palo Alto, CA). The volatile compounds were separated on a DB-Wax column $(30 \mathrm{~m} \times 0.25 \mathrm{~mm}$ i.d., $0.25 \mu \mathrm{m}$ film thickness, Agilent Technologies). The injection was performed in splitless mode $(0.7 \mathrm{~mm}$ splitless inlet liner, Supelco) and injector temperature was $220{ }^{\circ} \mathrm{C}$. The purge valve was opened at $0.5 \mathrm{~min}$ at a $50 \mathrm{~mL} / \mathrm{min}$ flow rate. Helium $(99.999 \%)$ was used as the carrier gas with a constant starting flow rate at $0.7 \mathrm{~mL} / \mathrm{min}$. The oven temperature was programmed as follows: $35{ }^{\circ} \mathrm{C}$ for $1 \mathrm{~min}, 5{ }^{\circ} \mathrm{C} / \mathrm{min}$ to $100{ }^{\circ} \mathrm{C}$, and $20^{\circ} \mathrm{C} / \mathrm{min}$ to a final temperature of $250{ }^{\circ} \mathrm{C}$ with a final holding time of $5 \mathrm{~min}$. The detector was fitted with an electron impact ionization source set at $230{ }^{\circ} \mathrm{C}$. The quadrupole temperature was set to $150{ }^{\circ} \mathrm{C}$ and the transfer line temperature was kept at $250{ }^{\circ} \mathrm{C}$. The solvent delay was set to $3 \mathrm{~min}$. Total ion chromatograms were collected scanning from $\mathrm{m} / \mathrm{z} 30$ to 150 at a rate of $3.06 \mathrm{scans} / \mathrm{s}$.

Volatile compounds were identified by comparison of their mass spectra and retention times with those of authentic standards, or by comparison of Kovats' retention indexes and mass spectrum, with those reported in the NIST Mass Spectral Search Program (version 2.0a) with $<80 \%$ as a cutoff to match compounds. The K.I.s were calculated from the retention times of $\mathrm{C} 6-\mathrm{C} 40 \mathrm{n}$-alkanes followed the recently method.[12]

\section{Statistical Analysis}

The figure was prepared by the Origin 8.5. All experiments were done in triplicates or more. 


\section{Results and Discussion}

\section{Total Microbial Counts of Watermelon Juice}

The total microbial counts of the watermelon juice during the storage is shown in Fig. 1. The initial count of the Unpasteurized was $5.85 \mathrm{Log}$ CFU/mL. The total microbial count of Unpasteurized was reduced to $1.85 \mathrm{Log}$ CFU/mL after the UHT treatemtn. The final total microbial count of the UHT treatments was reached $3.8 \mathrm{Log} \mathrm{CFU} / \mathrm{mL}$ on the $14^{\text {th }} \mathrm{d}$. Therefore, the UHT treatment were effective to reduced the initial count of the watermelon juice.

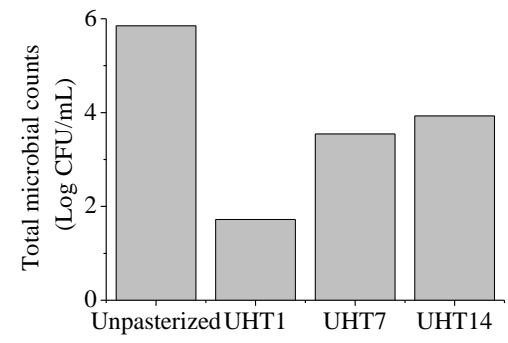

Figure.1. Effect of storage time on total microbial counts of the watermelon juice

\section{Aroma of Watermelon Juice}

The aroma of the juice was compared by the sensor array of 10 electrodes in the electric nose (Fig. 2). The dimensions of electrical responds were reduced by the principal component analysis. The main component 1 and 2 contributed $80.78 \%$ and $18.66 \%$ for the total watermelon aroma, respectively. The main component 1 represented the main aroma of the watermelon juice. The area of the Unpasteurized had no overlap with the other pasteurized watermelon juice. Consequently, the aroma of the UHT1, UHT7, and UHT14 was different to that of the Unpasteurized juice. Interestingly, the aroma of the berry juice pasteurized by the UHT is well maintained [13], while the heating at $90{ }^{\circ} \mathrm{C}$ for $28 \mathrm{~s}$ leads to a significant aroma change of the apple cider [14]. The UHT treatment was not good for the processing of the watermelon juice.

\section{Volatiles of Watermelon Juice}

Total 30, 29, 30, and 29 volatiles were indentified in the Unpasteurized, UHT1, UHT7 and UHT14, respectively (Table 1). The aldehyde, alcohol, ketone, alkane, and ester constituted $70.6 \%, 15.8 \%, 9.24 \%, 4.42 \%$, and $0.26 \%$, respectively, in the Unpasteurized watermelon juice. The acid was not found in the Unpasteurized watermelon juice. Consequently, the aldehyde was the main component in Unpasteurized watermelon juice.

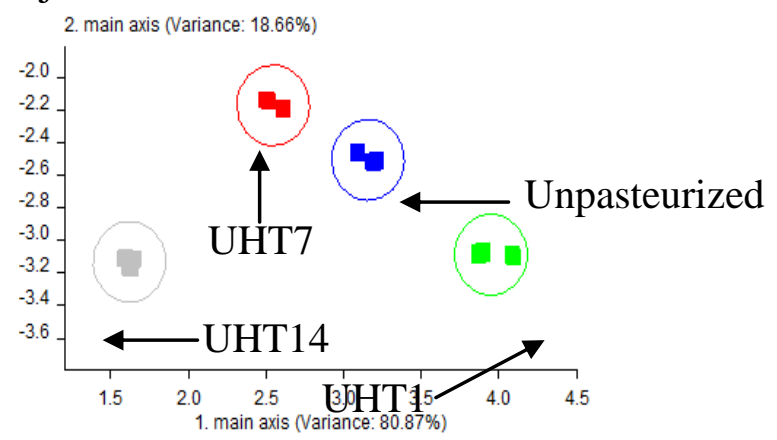

Figure.2. Effect of storage time on aroma of the watermelon juice

Remarkably, the aldehyde content of the Unpasteurized, UHT1, UHT7, and UHT14 
was $70.6 \%, 61.5 \%, 34.7 \%$, and $19.3 \%$, respectively. The aldehyde content reduced significantly during the storage. The aldehyde, such as the 1-Nonanal, (E, Z)-2,6-Nonadienal, and (2E)-2-Nonenal, was believed to be the main aroma of the watermelon juice. Hence, the aroma of the watermelon was reduced during the storage. On the other hand, the alcohol, acid, and ester content of the juice were enhanced during the storage.

Table 1-1. Volatiles of the watermelon juice during the storage

\begin{tabular}{|c|c|c|c|c|c|}
\hline Type & Volatiles & $\begin{array}{c}\text { Unpasteurize } \\
\mathrm{d}\end{array}$ & $\begin{array}{c}\text { UHT } \\
1\end{array}$ & $\begin{array}{l}\text { UHT } \\
7\end{array}$ & $\begin{array}{c}\text { UHT } \\
14\end{array}$ \\
\hline \multirow{3}{*}{ 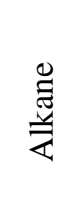 } & Tetradecane & 0.65 & $-*$ & - & - \\
\hline & 2-Pentylfuran & 3.08 & 5.52 & 1.24 & - \\
\hline & 1-Hexadecene & 0.69 & 1.05 & - & - \\
\hline & Subtotal & 4.42 & 6.57 & 1.24 & 0 \\
\hline \multirow{19}{*}{$\begin{array}{l}\overline{0} \\
\frac{1}{0} \\
\frac{8}{2}\end{array}$} & 1-Nonanol & - & - & 4.23 & 5.10 \\
\hline & (E)-2-Nonen-1-ol & 4.31 & 3.07 & 5.55 & 6.37 \\
\hline & (3Z)-3-Nonen-1-ol & 3.42 & 2.30 & 2.25 & 4.73 \\
\hline & (3E,6Z)-3,6-Nonadien-1-ol & - & - & 7.00 & 5.22 \\
\hline & Phenethyl alcohol & 3.06 & 4.04 & - & - \\
\hline & Hexyl alcohol & 0.93 & 0.18 & 1.74 & 2.40 \\
\hline & 2-Methyl-1-propanol & 0.99 & - & - & - \\
\hline & 1-Pentanol & - & - & - & 1.56 \\
\hline & 3-Methyl-1-butanol & 0.19 & - & - & - \\
\hline & (2E)-2-Hexen-1-ol & - & - & - & 1.70 \\
\hline & Capryl alcohol & 0.37 & 0.37 & 0.44 & 2.75 \\
\hline & 2-Hexyloctanol & - & 0.69 & - & - \\
\hline & 2-Octanol & 1.04 & - & - & - \\
\hline & Geraniol & 0.25 & - & - & - \\
\hline & 1-Octen-3-ol & - & - & - & 3.81 \\
\hline & (2E)-2-Octen-1-ol & - & - & - & 3.24 \\
\hline & (2E)-2-Undecen-1-ol & - & - & 3.36 & - \\
\hline & 1-Undecanol & - & - & 0.95 & - \\
\hline & Dodecenol & - & 0.33 & - & - \\
\hline
\end{tabular}


Table 1-2. Volatiles of the watermelon juice during the storage

\begin{tabular}{|c|c|c|c|c|c|}
\hline Type & Volatiles & $\begin{array}{c}\text { Unpasteurize } \\
\mathrm{d}\end{array}$ & $\begin{array}{c}\text { UHT } \\
1\end{array}$ & $\begin{array}{l}\text { UHT } \\
7\end{array}$ & $\begin{array}{c}\text { UHT } \\
14\end{array}$ \\
\hline & Dodecyl alcohol & 0.47 & - & - & - \\
\hline & (E)-2-dodecen-1-ol & - & - & 2.21 & - \\
\hline & 1-Tridecanol & 0.8 & 2.77 & 2.07 & - \\
\hline & 1-Tetradecanol & - & - & - & - \\
\hline & 1-Pentadecanol & - & 0.57 & - & - \\
\hline & 1-Hexadecanol & - & 0.53 & - & - \\
\hline & 1-Nonadecanol & - & 0.3 & - & - \\
\hline & 1,6-Octadien-3-ol & - & - & - & 3.58 \\
\hline & Subtotal & 15.83 & 15.15 & 29.8 & 40.46 \\
\hline \multirow{12}{*}{$\begin{array}{l}\frac{0}{0} \\
\frac{\mathbb{d}}{0} \\
\frac{\pi}{2}\end{array}$} & 1-Nonanal & 8.45 & 9.18 & - & - \\
\hline & (E,Z)-2,6-Nonadienal & 25.8 & 22.6 & 16.97 & 9.17 \\
\hline & (2E)-2-Nonenal & 10.1 & 9.22 & 8.15 & 6.62 \\
\hline & 2-Hexenal (E) & 4.32 & 4.21 & - & - \\
\hline & (E)-Hept-2-enal & 1.23 & - & - & - \\
\hline & Octanal & 5.21 & 3.22 & 2.05 & 1.01 \\
\hline & (E)-2-Octenal & 0.83 & - & 0.57 & - \\
\hline & Decanal & 6.08 & 5.87 & 4.32 & 2.14 \\
\hline & 2-Undecenal & - & - & 2.09 & - \\
\hline & (E)-2-Dodecenal & 7.65 & 5.69 & - & - \\
\hline & Tetradecanal & - & 0.66 & 0.59 & 0.34 \\
\hline & Pentadecanal & 0.58 & 0.89 & - & - \\
\hline & Subtotal & 70.25 & 61.54 & 34.74 & 19.28 \\
\hline \multirow{4}{*}{$\begin{array}{l}\stackrel{\mathscr{Z}}{0} \\
\stackrel{0}{0} \\
\check{U}\end{array}$} & 6-Methyl-5-hepten-2-one & 3.97 & 2.95 & 3.47 & 4.63 \\
\hline & 6,10-Dimethyl-5,9-undecadien-2-one & 2.83 & 5.31 & 4.18 & 1.96 \\
\hline & 3-Octanone & - & - & - & 0.58 \\
\hline & 3-Hydroxy-2-butanone & 1.47 & - & - & - \\
\hline
\end{tabular}


Table 1-3. Volatiles of the watermelon juice during the storage

\begin{tabular}{|c|c|c|c|c|c|}
\hline Type & Volatiles & $\begin{array}{l}\text { Unpasteurize } \\
\mathrm{d}\end{array}$ & $\begin{array}{l}\text { UHT } \\
1\end{array}$ & $\begin{array}{l}\text { UHT } \\
7\end{array}$ & $\begin{array}{c}\mathrm{UHT} \\
14\end{array}$ \\
\hline & 2-Pentadecanone & 0.33 & 2.46 & - & - \\
\hline & 2-Nonadecanone & 0.64 & - & - & - \\
\hline & $\begin{array}{c}\text { (Z)-6,10-Dimethyl-5,9-undecadien-2-o } \\
\text { ne }\end{array}$ & - & - & 3.77 & - \\
\hline & Subtotal & 9.24 & 10.72 & 11.42 & 7.17 \\
\hline \multirow{5}{*}{$\frac{\pi}{2}$} & Nonanoic acid & - & - & 5.75 & 7.96 \\
\hline & Acetic acid & - & - & 2.68 & 5.19 \\
\hline & 2-Methyl butyric acid & - & - & 2.71 & 3.87 \\
\hline & Hexanoic acid & - & - & 1.52 & 2.31 \\
\hline & Octanoic acid & - & - & 2.19 & 4.23 \\
\hline & Subtotal & 0 & 0 & 14.85 & 23.56 \\
\hline \multirow{6}{*}{ 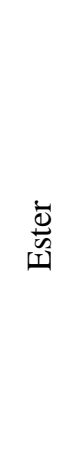 } & Octyl Formate & - & 0.22 & - & - \\
\hline & Isopropyl palmitate & - & 0.46 & - & 2.28 \\
\hline & Heptyl forMate & - & - & 1.04 & 2.13 \\
\hline & Dodecyl Acetate & - & - & 0.19 & 1.78 \\
\hline & Diisobutyl phthalate & 0.26 & 2.51 & 2.43 & 0.05 \\
\hline & Allyl hexanoate & - & 2.83 & 4.29 & 3.29 \\
\hline & Subtotal & 0.26 & 6.02 & 7.95 & 9.53 \\
\hline
\end{tabular}

The C9 alcohol and aldehyde are the key aroma of the watermelon juice. The 1-Nonanol, (E)-2-Nonen-1-ol, (3Z)-3-Nonen-1-ol, (3E, 6Z)-3, 6-Nonadien-1-ol, 1-Nonanal, (E,Z)-2,6-Nonadienal, and (2E)-2-Nonenal were designated as the typical volatiles of the watermelon in the watermelon juice. The content of the typical volatiles of the Unpasteurized, UHT1, UHT7, and UHT14 was $52.1 \%, 46.4 \%$, $44.2 \%$, and $37.2 \%$, respectively (Fig. 3). Hence, the watermelon aroma of the pasteurized watermelon juice was reduced with the storage time.

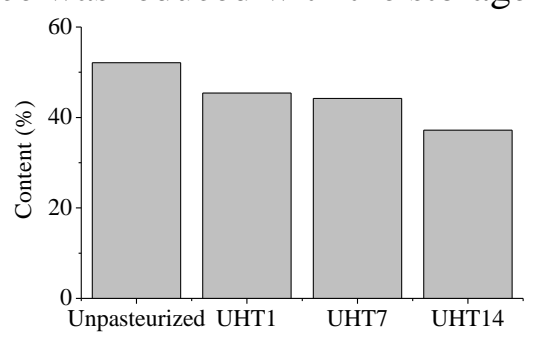

Figure.3. Effect of storage on typical volatiles of the watermelon juice 


\section{Acknowledge}

The authors are grateful to financial support of China Agriculture Research System (CARS-26), Beijing Academy of Agricultural and Forestry Sciences (KJCX20140204), and Beijing Key Laboratory of Fruits and Vegetable Storage and Processing (Z141105004414037).

\section{Reference}

[1] C. Zhang, B. Trierweiler, W. Li, P. Butz, Y. Xu, E. C. Rüfer, Y. Ma, X. Zhao, Comparison of thermal, ultraviolet-c, and high pressure treatments on quality parameters of watermelon juice, Food Chem. 126 (2011) 254-260.

[2] A. J. Edwards, B. T. Vinyard, E. R. Wiley, E. D. Brown, J. K. Collins, P. Perkins-Veazie, B. A. Clevidence, Consumption of watermelon juice increases plasma concentrations of lycopene and $\beta$-carotene in humans, J. Nut. 133 (2003) 1043-1050.

[3] J. K. Collins, G. Wu, P. Perkins-Veazie, K. Spears, P. L. Claypool, R. A. Baker, B. A. Clevidence, Watermelon consumption increases plasma arginine concentrations in adults, Nut. 23 (2007) 261-266.

[4] G. Wu, J. K. Collins, P. Perkins-Veazie, M. Siddiq, K. D. Dolan, K. A. Kelly, C. J. Meininger, Dietary supplementation with watermelon pomace juice enhances arginine availability and ameliorates the metabolic syndrome in Zucker diabetic fatty rats, J. Nut. 137 (2007) 2680-2685.

[5] S. Altaş, G. Kızıl, M. Kızıl, A. Ketani, P. I. Haris, Protective effect of Diyarbakır watermelon juice on carbon tetrachloride-induced toxicity in rats, Food Chem. Toxicol. 49 (2011) 2433-2438.

[6] A. Rahmat, R. Rosli, W. N. I. W. M. Zain, S. Endrini, H. A. Sani, Antiproliferative activity of pure lycopene compared to both extracted lycopene and juices from watermelon (Citrullus vulgaris) and papaya (Carica papaya) on human breast and liver cancer cell lines, J. Med. Sci. 2 (2002) 55-58.

[7] M. P. Tarazona-Díaz, F. Alacid, M. Carrasco, I. Martínez, E. Aguayo, Watermelon juice: potential functional drink for sore muscle relief in athletes, J. Agric. Food Chem. 61 (2013) 7522-7528.

[8] C. R. Loss, in Cornell University, Cornell University, Ithaca, NY 2006.

[9] H. F. Poliseli-Scopel, M. Hernández-Herrero, B. Guamis, V. Ferragut, Comparison of ultra high pressure homogenization and conventional thermal treatments on the microbiological, physical and chemical quality of soymilk, LWT 46 (2012) 42-48.

[10] C. Zhang, Y. Wang, Y. Ma, X. Zhao, W. Li, Effect of ultra-high temperature processing on quality of watermelon juice, Adv. Eng. Res. 39 (2015) 594-598.

[11] W. Jittanit, S. Wiriyaputtipong, H. Charoenpornworanam, S. Songsermpong, Effects of varieties, heat pretreatment and UHT conditions on the sugarcane juice quality, Chiang Mai J. Sci. 38 (2011) 116-125.

[12] X. Tang, H. He, Y. Liu, X. Zhao, Identification of aroma compounds in watermelon juice by SPME-GCMS, Acta Hort. 944 (2012) 183-191. 
[13] I. Dalmadi, K. Polyak-Feher, J. Farkas, Effects of pressure-and thermal-pasteurization on volatiles of some berry fruits, High Pressure Res. 27 (2007) 169-171.

[14] G. G. Rye, D. G. Mercer, Changes in headspace volatile attributes of apple cider resulting from thermal processing and storage, Food Res. Int. 36 (2003) 167-174. 